\title{
Determination of Heterocyclic Amines and Acrylamide in Agricultural Products with Liquid Chromatography-Tandem Mass Spectrometry
}

\author{
Kyung-Jun Lee ${ }^{1,2}$, Gae-Ho Lee ${ }^{1,2}$, HaeSol Kim ${ }^{3}$, Min-Seok $\mathrm{Oh}^{6}$, Seok-Chu ${ }^{3}$, In Ju Hwang ${ }^{6}$, \\ Jee-yeon Lee ${ }^{4}$, Ari Choi ${ }^{4}$, Cho-il Kim ${ }^{5}$ and Hyun-Mee Park ${ }^{6}$ \\ ${ }^{1}$ Korea Research Institute of Analytical Technology, Daejeon, Korea \\ ${ }^{2}$ Department of Chemistry, Chungnam National University, Daejeon, Korea \\ ${ }^{3}$ Department of Chemistry, Yonsei University, Seoul, Korea \\ ${ }^{4}$ Nutrition Policy \& Promotion Team, Korea Health Industry Development Institute, Chungcheongbuk-do, Korea \\ ${ }^{5}$ Bureau of Health Industry Promotion, Korea Health Industry Development Institute, Chungcheongbuk-do, Korea \\ ${ }^{6}$ Advanced Analysis Center, Korea Institute of Science and Technology, Seoul, Korea
}

(Received August 17, 2015; Revised September 10, 2015; Accepted September 17, 2015)

\begin{abstract}
Heterocyclic amines (HCAs) and acrylamide are unintended hazardous substances generated by heating or processing of foods and are known as carcinogenic and mutagenic agents by the animal experiments. A simple method was established for a rapid and accurate determination of 12 types of HCAs (IQ, MeIQ, Glu-P-1, Glu-P-2, MeIQx, Trp-P-1, Trp-P-2, PhIP, A $\alpha$ C, MeA $\alpha$, Harman and Norharman) and acrylamide in three food matrices (non-fat liquid, non-fat solid and fat solid) by isotope dilution liquid chromatography-tandem mass spectrometry (LC-MS/MS). In every sample, a mixture of internal standards including IQ- $\mathrm{d}_{3}$, MeIQx-d $\mathrm{d}_{3}$, PhIP- $\mathrm{d}_{3}$, Trp-P-2- ${ }^{13} \mathrm{C}_{2}-{ }^{15} \mathrm{~N}$ and MeA $\alpha \mathrm{C}-\mathrm{d}_{3}$ was spiked for quantification of HCAs and ${ }^{13} \mathrm{C}_{3}$-acrylamide was also spiked for the analysis of acrylamide. HCAs and acrylamide in sample were extracted with acetonitrile and water, respectively, and then two solid-phase extraction cartridges, ChemElut: HLB for HCAs and Accucat: HLB for acrylamide, were used for efficiently removing interferences such as pigment, lipid, polar, nonpolar and ionic compounds. Established method was validated in terms of recovery, accuracy, precision, limit of detection, limit of quantitation, and linearity. This method showed good precision (RSD $<20 \%$ ), accuracy $(71.8 \sim 119.1 \%)$ and recovery $(66.0 \sim 118.9 \%)$. The detection limits were $<3.1 \mathrm{ng} / \mathrm{g}$ for all analytes. The correlation coefficients for all the HCAs and acrylamide were $>0.995$, showing excellent linearity. These methods for the detection of HCAs and acrylamide by LC-MS/MS were applied to real samples and were successfully used for quantitative monitoring in the total diet study and this can be applied to risk assessment in various food matrices.
\end{abstract}

Key words: Heterocyclic amines, Acrylamide, Isotope dilution, Validation, LC-MS/MS, Agricultural products

\section{INTRODUCTION}

As the amount of unintended hazardous substances is increased during food production, processing, and cooking, consumer's interest towards these substances is increasing. Heterocyclic amines (HCAs) and acrylamide could be presented as the unintended harmful substances in cooked

Correspondence to: Hyun-Mee Park, Advanced Analysis Center, Korea Institute of Science and Technology, 5, Hwarang-ro 14-gil, Seongbuk-gu, Seoul 136-791, Korea

E-mail:phm4556@kist.re.kr

This is an Open-Access article distributed under the terms of the Creative Commons Attribution Non-Commercial License (http:// creativecommons.org/licenses/by-nc/3.0) which permits unrestricted non-commercial use, distribution, and reproduction in any medium, provided the original work is properly cited. foodstuffs (1) by the Maillard reaction. HCAs are known as a mutant substance, which emerges when heating (fried, broiled, or barbecued) foodstuffs rich in amino acids or creatine and are categorized into the amino carboline group or amino-imidazo-azaarene (AIA) group according to their chemical structures (2). The amino carboline group is generally known as pyrolytic HCAs because it is formed during the pyrolysis reaction with amino acids or proteins at $>300^{\circ} \mathrm{C}(2)$. Possible amino acids are tryptophan, glutamic acid, and phenylalanine, and possible proteins are globulin, casein, or creatine. AIAs are called thermic HCAs, with an imidazo functional group attached to quinolone, quinoxaline, or pyridine. The main precursors of AIAs are free amino acid, creatine, creatinine, sugar, pyrrole, and pyridine derivatives produced by the dehydration and cyclization reactions (2). Heterocyclic pyridine and pyrazine (IQ- 
and IQx-type) are produced by the Maillard reaction of hexose and free amino acid (2), Strecker degradation of free amino acid and additional transformation occurs by aldehyde and creatine, forming imidazoquinoline and imidazo- quinoxaline. The factors affecting the HCA production in the food are their precursors (amino acids, sugars, creatine, and creatinine), temperature, moisture, cooking conditions, and antioxidant. Chemical structures and precursors of

Table 1. Chemical structure and precursor of HCAs (2) and acrylamide (21)

\begin{tabular}{|c|c|c|c|}
\hline \multicolumn{4}{|c|}{ Amino carboline } \\
\hline Abbreviation & Full name & Molecular structure & Precursor \\
\hline Glu-P-1 & $\begin{array}{l}\text { 2-Amino-6-methyldipyrido[1,2-A:3',2'-D]imid- } \\
\text { azole Hydrochloride Hydrate }\end{array}$ & & Glutamic acid \\
\hline Glu-P-2 & $\begin{array}{l}\text { 2-Aminodipyrido[1,2-A:3',2'-D]imidazole } \\
\text { Hydrochloride }\end{array}$ & & Glutamic acid, casein \\
\hline Trp-P-1 & 3-Amino-1,4-dimethyl-5H-pyrido[4,3-b]indole & & Tryptophan \\
\hline Trp-P-2 & 3-Amino-1-methyl-5H-pyrido[4,3-b]indole & & Tryptophan \\
\hline $\mathrm{A} \alpha \mathrm{C}$ & 2-Amino-9H-pyrido[2,3-b]indole & & Soybean globulin \\
\hline $\mathrm{MeA} \alpha \mathrm{C}$ & 2-Amino-3-methyl-9H-pyrido[2,3-b]indole & & - \\
\hline Harman & 1-Methyl-9H-pyrido[3,4-b]indole & & Tryptophan \\
\hline
\end{tabular}


Table 1. Continued

\begin{tabular}{|c|c|c|c|}
\hline \multicolumn{4}{|c|}{ Amino carboline } \\
\hline Abbreviation & Full name & Molecular structure & Precursor \\
\hline Norharman & $9 H$-pyrido[3,4-b]indole & $\mathrm{H}$ & Tryptophan \\
\hline \multicolumn{4}{|c|}{ Amino imidazoazaarene } \\
\hline IQ & 2-Amino-3-methyl-3H-imidazo[4,5-f]quinoline & & $\begin{array}{l}\text { Creatine, Gly, Phc, } \\
\text { Ser, Glucose }\end{array}$ \\
\hline MeIQ & $\begin{array}{l}\text { 2-Amino-3,4-dimethyl-3H-imidazo[4,5-f]quino- } \\
\text { line }\end{array}$ & & Creatine, Ala, fructose \\
\hline MeIQx & $\begin{array}{l}\text { 2-Amino-3,8-dimethylimidazo[4,5-f]quinoxal- } \\
\text { ine }\end{array}$ & & $\begin{array}{l}\text { Creatine, Gly, Ala, } \\
\text { Thr, Lys, Glucose }\end{array}$ \\
\hline PhIP & $\begin{array}{l}\text { 2-Amino-1-methyl-6-phenylimidazo[4,5-b]pyri- } \\
\text { dine }\end{array}$ & & Creatine, Glucose, Tyr \\
\hline \multicolumn{4}{|c|}{ Acrylamide } \\
\hline $\mathrm{AA}$ & $\begin{array}{l}\text { Acrylamide } \\
\text { (2-Propenamide) }\end{array}$ & & Asparagine, Sugars \\
\hline
\end{tabular}

HCAs including full name and abbreviations are listed in Table 1. Acrylamide is a low-molecular-weight vinyl compound and is a colorless and odorless crystalline substance. It is easily soluble in water and rapidly polymerized by reacting with air (3) and is used to make polyacrylamide and its copolymers are used for the treatment of wastewater and purifying water in industries (4). According to the research of the Swedish National Food Administration, acrylamide was detected in the heat-treated potato products and other baked goods (5). Actually, potato products showed the highest amounts of acrylamide (6). When starchy foods are fried, roasted, or baked at temperatures $>120^{\circ} \mathrm{C}$, the Maillard reaction between asparagines and reducing sugars in the food results in the formation of acrylamide (3).

The carcinogenicity of HCAs was tested by many animal 
experiments. These results confirm that some HCAs cause colon, breast, and prostate cancer. Moreover, monkeys got liver cancer when IQ was dosed to them, which imply some HCAs are carcinogenic not only to the rodent, but also to the mammals (7). Currently, HCAs do not have international standard regulations; however, the International Agency for Research on Cancer (IARC) in the World Health Organization (WHO) distinguished seven kinds of HCAs (i) MeIQ, MeIQx, Glu-P-1, Glu-P-2, PhIP, A $\alpha$, and $\mathrm{MeA} \alpha \mathrm{C}$ as possible carcinogens to humans (Group 2B) and (ii) IQ as a probable carcinogen to humans (Group 2A) (8). In 1994, acrylamide has been classified as a probable carcinogen to human (Group 2A) by the IARC (9). The potential risk of acrylamide in food to the public health has been considered by many government agencies and national authorities (10) and they performed risk assessments of acrylamide in food and concluded that efforts should be made to reduce the acrylamide levels to as low as possible. A long-term exposure to acrylamide may damage the nervous system in both humans and animals to a certain extent (11).

In the previous literatures, the extraction and clean-up procedures of HCAs were performed mostly based on the method of Gross (12) and Grüter (13) by using three cartridges: Extrelut, propylsulfonic acid (PRS) and $\mathrm{C}_{18}$. After a certain amount of sodium hydroxide is added to meat and seafood, extraction is performed, followed by the adsorption to ChemElut and the eluate flows out to PRS and $\mathrm{C}_{18}$ in a series to clean up interferences. In other literatures, HCAs are extracted with MCX (14) (Mixed-mode: Cation exchange), SCX (15) (Strong cation exchange)- $\mathrm{C}_{18}$, and LiChrolut EN (16). For the detection of HCAs, LC-MS (17), LC-MS/MS $(18)$ or DAD $(19,20)$ are used. In the pretreatment of acrylamide, sample extraction was mostly performed by the liquid-liquid extraction method and several studies also used matrix solid-phase dispersion (21). Mainly, solid-phase extraction (SPE) was used for the elimination of matrices by additional step. Accucat, Oasis HLB, and multi mode (9) were commonly used in acrylamide analysis. The analytical instruments such as GC-MS (21), GC-MS/MS (5) and LC-MS/MS (22) were used for qualification and quantitation.

Isotope dilution can be used efficiently for analyzing organic compounds in various food matrices. It can increase accuracy and precision in the real sample analysis. Calibration curve and concentration calculations are obtained with the ratio between sample and internal standard responses. In the previous analytical methods for HCAs, internal standards have been used such as caffeine, 1-naphthylamine, and L-norleucine (14). 2-Amino-3,4,7,8-tetramethyl-3Himidazo[4,5-f] quinoxaline (4,7,8-TriMeIQx) (19) has also been used as the internal standard for 10 species of HCAs. Isotopically labelled materials such as $\mathrm{PhIP}_{3} \mathrm{~d}_{3}$ (18), MeIQX-d $\mathrm{d}_{3}$ (23) and ${ }^{14} \mathrm{C}$-IQ (17) have been used as a single internal standard for several analytes. However, this cannot solve the problems such as the matrix effect, low recovery, and errors from calibration because one internal standard cannot represent many different kinds of analytes. Therefore, several isotope-labelled standards are needed to analyse different types of analytes.

As previous analytical methods have been studied mainly for fat foods for HCAs (20) and potatoes for acrylamide (6), they cannot be applied to various food matrices, therefore, it needs a fast and simple extracting and clean-up procedure appropriate for the characteristics and properties of each matrix. In this study, for the analysis of acrylamide and 12 species of HCAs (IQ, MeIQ, Glu-P-1, Glu-P-2, MeIQx, PhIP, Trp-P-1, Trp-P-2, A $\alpha \mathrm{C}, \mathrm{MeA} \alpha \mathrm{C}$, Harman, and Norharman) using LC-MS/MS in the various agricultural matirces, foodstuffs are divided into three groups: non-fat solid, non-fat liquid, and fat solid. This study aimed to achieve significant accuracy, precision, and recovery by applying different internal standards to each analyte. Moreover, the performance of the established analytical method was evaluated in terms of linearity, accuracy, precision, limit of detection (LOD), and limit of quantitation (LOQ), and its applicability to real samples was investigated to confirm it as the analytical method of monitoring HCAs and acrylamide for the risk assessment in the total diet study.

\section{MATERIALS AND METHODS}

Reagents and instruments. All chemicals and solvents were of HPLC or analytical grade. HCA standards (IQ, MeIQ, MeIQx, Glu-P-1, Glu-P-2, Norharman, Harman, PhIP, Trp-P-1, Trp-P-2, A $\alpha \mathrm{C}$, and $\mathrm{MeA} \alpha \mathrm{C}$ ) and isotopically labeled internal standards (IQ- $\mathrm{d}_{3}$, MeIQx-d $\mathrm{d}_{3}$, Harman$\mathrm{d}_{3}$, PhIP- $\mathrm{d}_{3}$, Trp-P-2- ${ }^{13} \mathrm{C}_{2},{ }^{15} \mathrm{~N}$, and MeA $\alpha \mathrm{C}-\mathrm{d}_{3}$ ) were purchased from Toronto Research Chemicals Inc. (Toronto, Canada). Every standard solution $(1 \mathrm{mg} / \mathrm{mL})$ was dissolved in methanol, and the mixture solution was prepared by the dilution, and all the standard solutions were stored in a refrigerator $\left(-4^{\circ} \mathrm{C}\right)$ until analysis. Caffeic acid, ammonium formate, and formic acid were purchased from SigmaAldrich (St. Louis, MO, USA). All the HPLC grade solvents for the pretreatment and mobile phase were purchased from J. T. Baker (Phillipsburg, NJ). ChemElut (20 $\mathrm{mL}$, unbuffered) was obtained from Agilent Technology (Santa Clara, CA, USA). Oasis HLB cartridge (60 mg, $3 \mathrm{~mL}$ ) was purchased from Waters Corporation (Dublin, Ireland). Power Sonic 420 sonicator purchased from Hawshin Technology (Gwangju, Korea) and C-SK shaker purchased from Changshin Scientific (Pocheon, Korea) were used for the pretreatment. For concentrating the extracts, a GMG-2000 evaporator from EYELA (Tokyo, Japan) was used. Nalgene Teflon tube and Pyrex glass tubes were purchased from Thermo Science (NY, USA).

Acrylamide standards and isotopically labeled internal 
Table 2. Optimized MS conditions

\begin{tabular}{|c|c|c|c|c|c|c|}
\hline Compound & MRM transition & $\mathrm{DP}^{\mathrm{a}}$ (volts) & $\mathrm{EP}^{\mathrm{b}}$ (volts) & $\mathrm{CE}^{\mathrm{c}}$ (volts) & CEP $^{\mathrm{d}}$ (volts) & $\mathrm{CXP}^{\mathrm{e}}$ (volts) \\
\hline Glu-P-2 & $185.1 \rightarrow 78.0$ & 61 & 9.5 & 47 & 12 & 4 \\
\hline IQ & $199.1 \rightarrow 184.1$ & 56 & 5 & 33 & 12 & 4 \\
\hline Glu-P-1 & $199.1 \rightarrow 92.0$ & 96 & 5 & 47 & 14 & 4 \\
\hline MeIQ & $213.1 \rightarrow 198.1$ & 61 & 10.5 & 33 & 14 & 4 \\
\hline MeIQx & $214.1 \rightarrow 199.2$ & 86 & 4.5 & 33 & 12 & 4 \\
\hline Norharman & $169.1 \rightarrow 115.1$ & 66 & 9.5 & 45 & 10 & 4 \\
\hline Harman & $183.1 \rightarrow 115.1$ & 66 & 11 & 45 & 14 & 4 \\
\hline Trp-p-2 & $198.1 \rightarrow 154.2$ & 61 & 10.5 & 39 & 16 & 4 \\
\hline PhIP & $225.1 \rightarrow 210.2$ & 86 & 4.5 & 35 & 12 & 4 \\
\hline Trp-p-1 & $212.1 \rightarrow 167.1$ & 61 & 4.5 & 47 & 12 & 4 \\
\hline $\mathrm{AaC}$ & $184.1 \rightarrow 140.1$ & 56 & 10.5 & 41 & 14 & 4 \\
\hline $\mathrm{MeAaC}$ & $198.1 \rightarrow 181.2$ & 131 & 5 & 29 & 16 & 4 \\
\hline Acrylamide & $72.0 \rightarrow 55.0$ & 31 & 4.5 & 17 & 18 & 4 \\
\hline $\mathrm{AA}-{ }^{13} \mathrm{C}_{3}$ & $75.0 \rightarrow 58.0$ & 31 & 4 & 15 & 18 & 4 \\
\hline IQ-d ${ }_{3}$ & $202.1 \rightarrow 184.2$ & 86 & 10.5 & 33 & 12 & 4 \\
\hline MeIQx-d ${ }_{3}$ & $217.1 \rightarrow 199.1$ & 86 & 10 & 33 & 14 & 4 \\
\hline Harman-d $\mathrm{d}_{3}$ & $186.0 \rightarrow 115.1$ & 81 & 10.5 & 45 & 12 & 4 \\
\hline PhIP-d & $228.1 \rightarrow 210.1$ & 71 & 4.5 & 39 & 14 & 4 \\
\hline Trp-p-2 $-{ }^{13} \mathrm{C}_{2},{ }^{15} \mathrm{~N}$ & $200.9 \rightarrow 155.1$ & 86 & 3.5 & 41 & 16 & 4 \\
\hline $\mathrm{MeAaC}-\mathrm{d}_{3}$ & $201.1 \rightarrow 184.2$ & 81 & 10.5 & 31 & 12 & 4 \\
\hline
\end{tabular}

a: Declustering Potential, b: Entrance Potential, c: Collision Energy, d: Collision Cell Entrance Potential, e: Collision Cell Exit Potential.

standard were purchased from Accu Standard Inc. (St Market, CT, USA) and Cambridge Isotope Laboratories, Inc. (Tewksbury, MA, USA). Every standard solution was dissolved in water, and the mixture solution was prepared by the dilution. All the standard solutions were stored in a refrigerator $\left(-4^{\circ} \mathrm{C}\right)$ until the analysis. All the HPLC grade solvents for the pretreatment and mobile phase were purchased from Sigma-Aldrich (St. Louis, MO, USA). Bond Elut Accucat cartridge $(600 \mathrm{mg}, 3 \mathrm{~mL})$ was obtained from Agilent Technology (Santa Clara, CA, USA). Oasis HLB cartridge $(200 \mathrm{mg}, 6 \mathrm{~mL})$ was purchased from Waters Corporation (Dublin, Ireland). A centrifuge machine was purchased from Hanil Science Industrial (Incheon, Korea).

LC-MS/MS analysis. The HCA analysis was performed using an Agilent 1260 series HPLC system (Agilent Technologies, Palo Alto, CA, USA) coupled to API 3200 triple quadrupole mass spectrometer (MDS Sciex, Concord, ON, Canada) equipped with electrospray ionization (ESI). All the analytes were separated by an Atlantis T3 column $(2.1 \times$ $100 \mathrm{~mm}$, i. d., $3 \mu \mathrm{m}$; Waters Corporation, Dublin, Ireland), maintained at $35^{\circ} \mathrm{C}$. The mobile phase was $30 \mathrm{mM}$ ammonium formate $(\mathrm{pH} 3.7)$ with water $(\mathrm{A})$ and $100 \%$ acetonitrile (B), and gradient condition was as follows: $90 \%$ mobile phase A for $2 \mathrm{~min} ; 2 \sim 2.5 \mathrm{~min}$ held at $87 \% \mathrm{~A} ; 2.5 \sim$ $4 \mathrm{~min}, 87 \sim 86 \% \mathrm{~A} ; 4 \sim 7.5 \mathrm{~min}, 86 \sim 66 \% \mathrm{~A} ; 7.5 \sim 8.5 \mathrm{~min}, 66 \sim$ $50 \% \mathrm{~A} ; 8.5 \sim 11$ held at 50\% A; 11 13 min, 50 0\% A; and then returned to the initial condition for $13 \sim 20 \mathrm{~min}$. The flow rate was $0.25 \mathrm{~mL} / \mathrm{min}$ and $5 \mu \mathrm{L}$ aliquot of the extracts was injected into the LC-MS/MS. A triple quadrupole mass spectrometer was used to detect the analytes by ESI in the positive mode. For selective and sensitive analysis, multiple reaction monitoring (MRM) mode was used to detect the product ions. The optimized parameters for MS were as

\section{(A)}

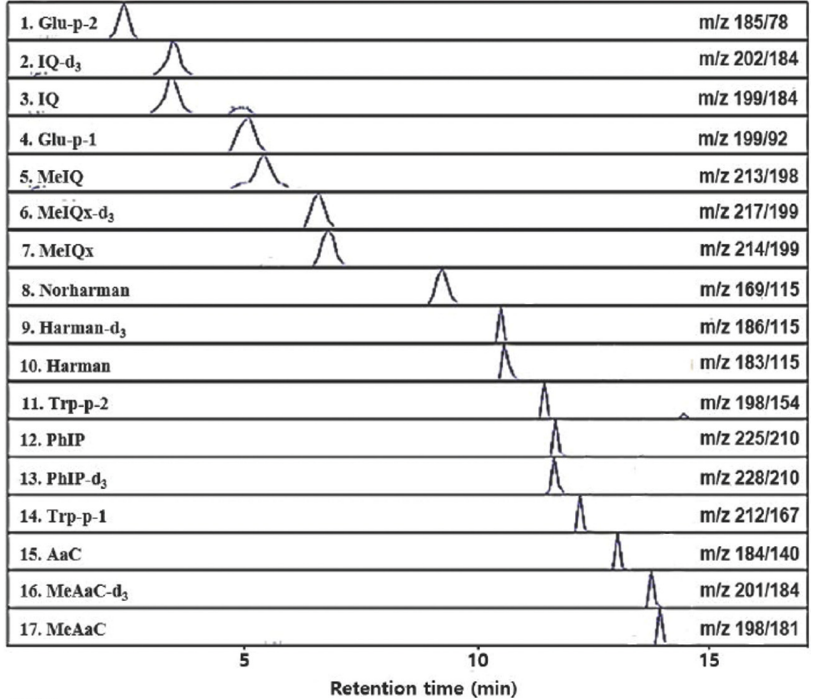

(B)

\begin{tabular}{|lcr|}
\hline 1. AA & $\bigwedge$ & $\mathrm{m} / \mathrm{z} 185 / 78$ \\
\hline 2.AA-13 $\mathrm{C}_{3}$ & $\bigwedge$ & $\mathrm{m} / \mathrm{z} 185 / 78$ \\
\hline & $\begin{array}{c}\dot{5} \\
\text { Retention time (min) }\end{array}$ & 10 \\
\hline
\end{tabular}

Fig. 1. MRM chromatograms for (A) HCAs and (B) acrylamide (AA). 
follows: ionspray voltage, $5,500 \mathrm{~V}$ at $550^{\circ} \mathrm{C}$; curtain gas, $25 \mathrm{psi}$; nebulizing gas, $50 \mathrm{psi}$; and heating gas, $50 \mathrm{psi}$. The mass conditions are listed in detail in Table 2, and the chromatograms are shown in Fig. 1.

The acrylamide analysis was performed by using a Shimadzu 20AD HPLC system (Kyoto, Japan) coupled to API 3200 triple quadrupole mass spectrometer (MDS Sciex, Concord, ON, Canada) equipped with electrospray ionization (ESI). Analytes were separated with matrices using an Aqua C18 column $(2 \times 250 \mathrm{~mm}$, i. d., $5 \mu \mathrm{m}$; Torrance, CA, USA), maintained at $40^{\circ} \mathrm{C}$. The mobile phase was eluted by $0.2 \%$ acetic acid and $0.5 \%$ methanol in water by the isocratic mode. The flow rate was $0.2 \mathrm{~mL} / \mathrm{min}$ and $25 \mu \mathrm{L}$ was injected into the LC-MS/MS. A triple quadrupole mass spectrometer was used to detect the analytes by ESI in the positive mode. For selective and sensitive analysis, MRM mode was used to detect the product ions. The optimized parameters for the MS were as follows: ionspray voltage, $5,000 \mathrm{~V}$ at $550^{\circ} \mathrm{C}$; curtain gas, $25 \mathrm{psi}$; nebulizing gas, $50 \mathrm{psi}$; and heating gas, $50 \mathrm{psi}$.

Extraction and clean-up procedures. For sample pretreatment, samples were classified into non-fat solid, non-fat liquid, and fat solid, according to the contents of fat, which with fat content $>20 \%$ were classified as fatty. Three types of samples, rice porridge, apple juice, and peanut butter, were used in the method validation as the matrix.

Heterocyclic amines: The method for twelve HCAs was modified to simplify the procedure described by Gross and Grüter (13).

Non-fat solid (Rice porridge): Rice porridge ( $5 \mathrm{~g}$ ) was spiked with $100 \mathrm{ng}$ of the internal standard mixture, $12 \mathrm{~mL}$ of $1 \mathrm{M}$ sodium hydroxide, $14 \mathrm{~mL}$ of acetonitrile, and $1 \mathrm{~mL}$ of methanol. The sample was shaken for $10 \mathrm{~min}$ in a mechanical shaker to homogenize it and then separated by centrifugation at $7,000 \mathrm{rpm}$ for $10 \mathrm{~min}$ at $25^{\circ} \mathrm{C}$. The supernatant was loaded onto $20 \mathrm{~mL}$ ChemElut for $10 \mathrm{~min}$ and then eluted with $80 \mathrm{~mL}$ of a mixture of methylene chloride:ethyl acetate $(3: 1, \mathrm{v} / \mathrm{v})$. The eluate was evaporated and redissolved in $2 \mathrm{~mL}$ water-methanol $(9: 1, \mathrm{v} / \mathrm{v})$, and $0.5 \mathrm{~mL}$ of $1 \mathrm{M}$ sodium hydroxide. This reconstituted solution was loaded onto HLB cartridge preconditioned with $1 \mathrm{~mL}$ of methanol and distilled water. The HLB cartridge was washed with $2 \mathrm{~mL}$ of $2 \%$ ammonia solution and eluted by using $3 \mathrm{~mL}$ of $2 \%$ acetic acid containing $90 \%$ methanol. Aliquot $(5 \mu \mathrm{L})$ of the eluate was injected into LC-MS/MS.

Non-fat liquid (Apple juice): Apple juice (15 g) was spiked with $100 \mathrm{ng}$ of the internal standards, followed by the addition of $0.5 \mathrm{~mL}$ of $1 \mathrm{M} \mathrm{NaOH}$. The mixture was shaken for 10 min to homogenize it, and the resulting solution was adsorbed for $10 \mathrm{~min}$ after loading onto ChemElut and eluted with $80 \mathrm{~mL}$ of dichloromethane and ethyl acetate mixture at a $\mathrm{v}: \mathrm{v}$ ratio of $3: 1$. This eluate was evapo- rated in a rotary evaporator, and then $2 \mathrm{~mL}$ of distilled water : $\mathrm{MeOH}(9: 1, \mathrm{v} / \mathrm{v})$ and $0.5 \mathrm{~mL}$ of $1 \mathrm{M} \mathrm{NaOH}$ were added to the effluent. This reconstituted solution was loaded onto an HLB cartridge, preconditioned with $1 \mathrm{~mL}$ of methanol and $1 \mathrm{~mL}$ of distilled water. The HLB cartridge was washed with $2 \mathrm{~mL}$ of $2 \%$ ammonia solution and eluted by $3 \mathrm{~mL}$ of $2 \%$ acetic acid containing $90 \%$ methanol and eluted with $3 \mathrm{~mL}$ of $2 \%$ acetic acid $(90 \% \mathrm{MeOH})$ and were transferred into vials for the analysis by LC-MS/MS.

Fat solid (Peanut butter): Peanut butter ( $4 \mathrm{~g}$ ) was spiked with $100 \mathrm{ng}$ of the internal standards, followed by the addition of $15 \mathrm{~mL}$ of $1 \mathrm{M} \mathrm{NaOH}$ and $15 \mathrm{~mL}$ of acetonitrile. After, shaking for $10 \mathrm{~min}$, the mixture was centrifuged for $10 \mathrm{~min}$ at 7,000 rpm to homogenize the mixture and separate the layers. This procedure was repeated twice, and then the supernatants were evaporated using a rotary evaporator. The residue was adsorbed for $10 \mathrm{~min}$ after loading onto ChemElut and eluted with $80 \mathrm{~mL}$ of dichloromethane and ethyl acetate $(3: 1 \mathrm{v}: \mathrm{v})$. The eluate was evaporated using a rotary evaporator. Distilled water $(2 \mathrm{~mL})$ and $\mathrm{MeOH}$ at a ratio $9: 1$ and $0.5 \mathrm{~mL}$ of $1 \mathrm{M} \mathrm{NaOH}$ were added to the eluate and loaded onto the HLB cartridges conditioned with $1 \mathrm{~mL}$ of distilled water and $1 \mathrm{~mL}$ of $\mathrm{MeOH}$, washed with $2 \mathrm{~mL}$ of $2 \%$ ammonia solution, eluted with $3 \mathrm{~mL}$ of $2 \%$ acetic acid $(90 \% \mathrm{MeOH})$, and finally transferred to vials for the analysis by LC-MS/MS.

Acrylamide: The pretreatment of acrylamide was performed by the FDA method (24) for the three matrices (rice porridge, apple juice and peanut butter).

(a) Crushed sample $(1 \mathrm{~g})$ was weighed in a $50 \mathrm{~mL}$ polypropylene tube. (b) Internal standard solution $\left({ }^{13} \mathrm{C}_{3}\right.$-labeled acrylamide, $200 \mathrm{ng} / \mathrm{mL}, 1 \mathrm{~mL}$ ) was added to the tube, followed by adding $9 \mathrm{~mL}$ of water to the test portion. The tube was shaken by hand or vortexed briefly to disperse test portion in water prior to the mixing. (c) Mixing was performed for $20 \mathrm{~min}$ in a rotating shaker. (d) The sample was centrifuged at 3,500 rpm for $20 \mathrm{~min}$. Aliquot $(5 \mathrm{~mL})$ was filtered using a $0.45 \mu \mathrm{m}$ PTFE syringe filter (Millipore, Bedford, MA, USA). (e) OASIS HLB cartridge was conditioned with $3.5 \mathrm{~mL}$ methanol, followed by $3.5 \mathrm{~mL}$ of water. Methanol and water effluent were discarded. (f) OASIS HLB cartridge was loaded with $1.5 \mathrm{~mL}$ extract. The extract was allowed to pass completely through the sorbent material. The column was eluted with $0.5 \mathrm{~mL}$ water and discarded. Elution was performed with additional $1.5 \mathrm{~mL}$ water and collected for following Accucat cartridge cleanup. (g) The outside of the Accucat SPE cartridge was marked at a height of $1 \mathrm{~mL}$ volume above the sorbent bed. Accycat SPE cartridge was conditioned with $2.5 \mathrm{~mL}$ methanol, followed by $2.5 \mathrm{~mL}$ of water. Methanol and water effluent were discarded. Extract $(1.5 \mathrm{~mL})$ collected in step (f) was loaded and eluted to $1 \mathrm{~mL}$ mark before collecting the remainder of the eluate, and $2 \mathrm{~mL}$ of sample was transferred to an amber auto-sampler vial for LC/MS/MS analysis. 
Sample preparation. Eight types of agricultural products (apple juice, vinegar, flour, cereal, jam, chocolates, cookies, and potato chip) were analysed in this study. Representative foods were collected from 18 mega-markets in nine metropolitan cities (Seoul, Pusan, Incheon, Daegu, Daejeon, Kwangju, Ulsan, Suwon and Changwon) nationwide and made into composites by pooling them for total diet study. Matrix samples for validation were apple juice, peanut butter and rice porridge purchased from the retail markets. All samples were analysed according to the optimized procedure.

\section{RESULTS AND DISCUSSION}

Sample pretreatment. Pretreatment method of twelve HCAs was modified to simplify the procedure described by Gross and Grüter (13) and method for acrylamide was followed FDA method (24) for the three matrices (rice porridge, apple juice and peanut butter). In the analysis of HCAs, $1 \mathrm{M} \mathrm{NaOH}$ was added to adjust $\mathrm{pH}$ to alkaline $(\mathrm{pH}$ 13.5) and acetonitrile was selected as the extraction solvent, which effectively eliminate lipid. Volume of the $\mathrm{NaOH}$ and acetonitrile was different depending on the matrix. For example, in non-fat liquid (apple juice) only $1 \mathrm{~mL}$ of $1 \mathrm{M} \mathrm{NaOH}$ was added and there was no need for acetonitrile extraction. In the preliminary study, we performed optimization of appropriate cartridges, elution solvents, and solvent composiotions, which are not shown. Cartridges of HLB, QuEChERS (PSA $400 \mathrm{mg}, \mathrm{MgSO}_{4}$ $1200 \mathrm{mg}$ ), QuEChERS (PSA $400 \mathrm{mg}, \mathrm{MgSO}_{4} 1200 \mathrm{mg}$, GCB $400 \mathrm{mg}$ ), and Chem Elut were examined and combination of Chem Elut and HLB was used as it gave best result. As the eluent for Chem Elut, methylene chloride:ethylacetate $(3: 1)$ was selected from the comparison of the several solvent compositions (methylene chloride:ethylacetate, $1: 0,3: 1,4: 1,1: 1,1: 4,0: 1$ ). In addition, methanol contents as the eluent of HLB was compared with the $30,50,70,90 \%$ methanol containing $2 \%$ acetic acid and $90 \%$ methanol was selected because it showed best recovery for all analytes In the preliminary study of acrylamide, we firstly examined FDA method which represents for all foods and found that this method can be applied to three matrices (non-fat solid, non-fat liquid and fat solid) without any modifications. HLB clean-up after water extraction was used and followed by Accucat clean-up according to the FDA method through all samples in this study.

Method validation. To evaluate the effectiveness of the newly developed analytical method fitted to the three matrices, validation was performed using the parameters such as selectivity, recovery, accuracy, precision, linearity, LOD, and LOQ and verified with the criteria assigned in the CODEX guideline CAC/GL 71-2009. Samples fortified with all the analytes at their target concentrations (low, medium and high) were extracted and analyzed for the method verification.

Selectivity was validated by comparing the chromatogram to ensure that no interfering peaks were present at the retention times of $12 \mathrm{HCAs}$ and acrylamide. The representative chromatograms with that standards and internal standards are shown in Fig. 1, indicating good peak separation with no interfering peaks.

Calibration curves for the matrix sample spiked with the standards were obtained by plotting the peak area ratio (y) versus the concentration $(\mathrm{x})$ and verified by the correlation coefficient $\left(\mathrm{R}^{2}\right)$ calculated by the weighted least-square linear regression method. The range of calibration curve was 10 200 ng and 1 400 ng/mL for the HCAs and acrylamide. The calibration curves (not shown) exhibited good linearity with $\mathrm{R}^{2}>0.995$.

Five replicates of the fortified samples $(10,50$ and $100 \mathrm{ng}$ for HCAs and 10, 100 and $500 \mathrm{ng} / \mathrm{g}$ for acrylamide) were determined for recovery, accuracy, and intra-day precision. Inter-day precision was analysed on the five different days in the same way. The precision was expressed as the relative standard deviation (RSD, \%) and the accuracy was expressed as the recovery (\%) of the mean observed concentration to the nominal concentration. Both the precision and accuracy data are summarized in Table 3. Intra-day precisions were in the range 1.6 13.3\% RSD for nonfatty matrices and $2.0 \sim 19.9 \%$ for fatty matrix and these results are well within the acceptance range (RSD $<20 \%$ ). Interday precisions (not shown in Table) were in the ranges 0.9 $12.5 \%$ and $2.5 \sim 14.8 \%$ for nonfat matrices and fat solid, respectively, and are in the acceptable range.

The accuracies were in the ranges $71.8 \sim 119.1 \%$ and $75.9 \sim 115.0 \%$ for nonfatty matrices and fatty solid, respectively, and are well within CODEX criteria (70 120\%), for which the acceptable range is different depending on the concentrations. Highly reproducible accurate results demonstrate the reliability of this method for residue analyses. Analyte-free matrices were used to evaluate the extraction recovery. Using the peak areas of analytes obtained by diluted standard solutions spiked into extracts after the extraction as A, and the peak areas of the diluted standard solutions spiked before extraction as $\mathrm{B}$, the extraction recoveries were calculated as extraction recovery $(\%)=\mathrm{B} /$ $\mathrm{A} \times 100$. The extraction recoveries (not shown in Table) were in the range $70.9 \sim 118.9 \%$ and $72.8 \sim 102.6 \%$ for nonfatty matrices and for fatty solid, respectively, except for Trp-P-2 $(66.0 \%)$. The extraction recovery of Trp-P-2 was poor $(<70 \%)$; however calibration curves were derived from the spiked matrix and accuracy $(93.1 \%)$ was within the criteria $(70 \sim 120 \%)$. Therefore, this method can be applicable to real sample analysis.

To determine the LOD and LOQ, $10 \mathrm{ng}$ of HCA and acrylamide standards were spiked into each matrix, and five replicates were analysed. The LOD was calculated as 3.3 


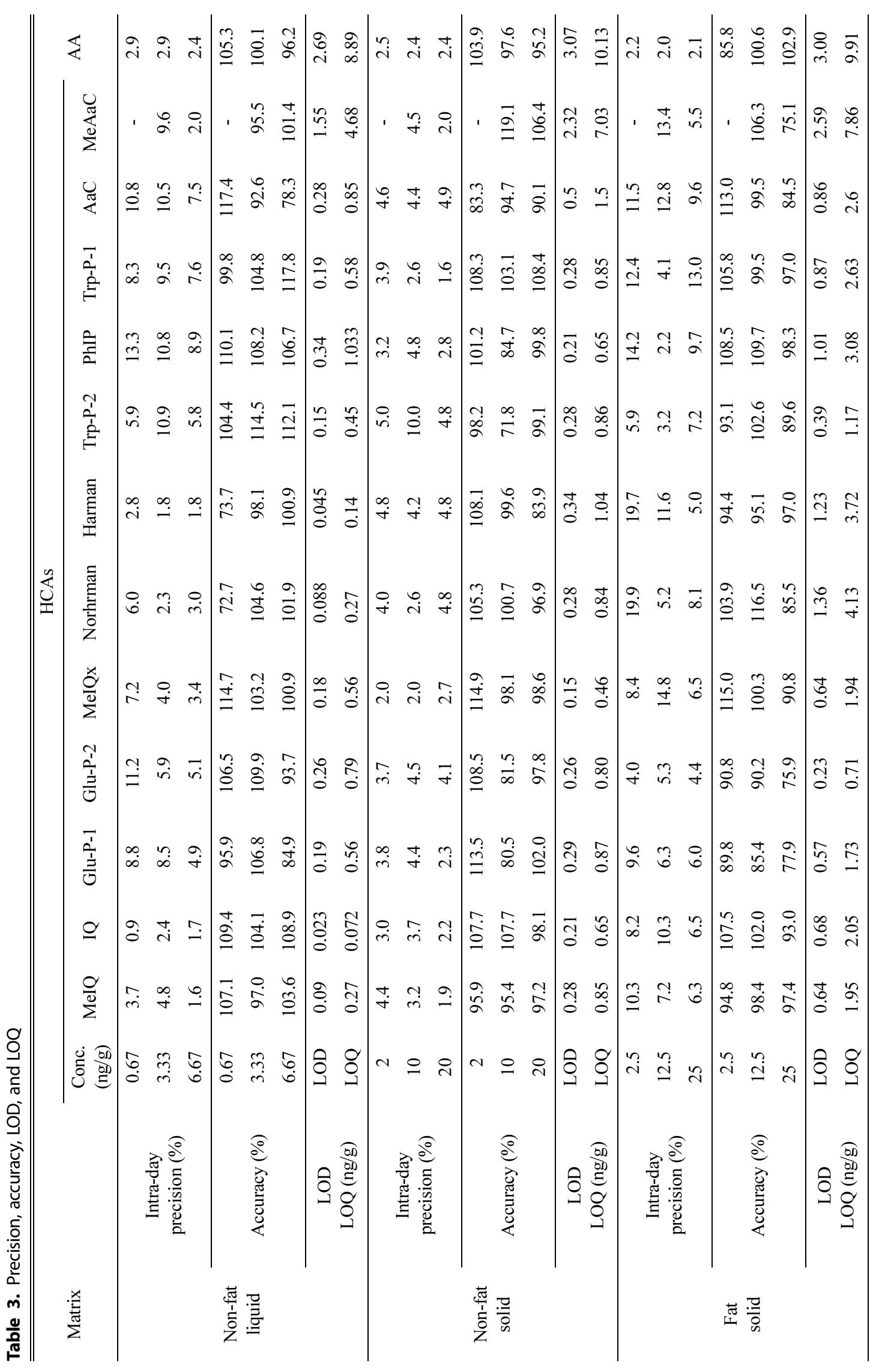


Table 4. Comparison of the results of this study with literature

\begin{tabular}{|c|c|c|c|c|c|c|c|}
\hline \multirow{2}{*}{ Matrix } & \multirow{2}{*}{ Sample } & \multicolumn{3}{|c|}{ Literature data $(\mathrm{ng} / \mathrm{g})$} & \multicolumn{3}{|c|}{ This study (ng/g) } \\
\hline & & Harman* & Norharman* & $\mathrm{AA}^{* *}$ & Harman & Norharman & AA \\
\hline \multirow{2}{*}{$\begin{array}{l}\text { Non-fat } \\
\text { liquid }\end{array}$} & $\begin{array}{l}\text { Fruit juice } \\
\text { (apple juice) }\end{array}$ & ND-1.8 & ND-5.5 & - & ND & $0.10 \pm 0.00$ & ND \\
\hline & Vinegar & ND-14.3 & ND -3.5 & - & $2.04 \pm 0.20$ & $1.91 \pm 0.15$ & ND \\
\hline \multirow{3}{*}{$\begin{array}{l}\text { Non-fat } \\
\text { solid }\end{array}$} & Flour & ND-0.8 & ND & - & ND & $0.53 \pm 0.06$ & ND \\
\hline & Cereal & ND-91.7 & ND -187.4 & $11-1,057$ & $1.40 \pm 0.10$ & $6.80 \pm 0.56$ & $\begin{array}{c}57.28 \pm 6.56 \text { (almond) } \\
47.38 \pm 1.64 \text { (normal) } \\
162.18 \pm 20.22 \text { (chocolate) }\end{array}$ \\
\hline & Jam & ND-0.41 & ND -1.07 & - & $2.20 \pm 0.30$ & ND & ND \\
\hline \multirow{3}{*}{$\begin{array}{l}\text { Fat } \\
\text { solid }\end{array}$} & Chocolates & $5.7-16.6$ & $4.14-10.9$ & ND-909 & $\begin{array}{c}6.73 \pm 0.63 \text { (pie) } \\
8.50 \pm 0.10 \text { (chip) }\end{array}$ & $\begin{array}{c}4.60 \pm 0.46 \text { (pie) } \\
8.03 \pm 0.25 \text { (chip) }\end{array}$ & $\begin{array}{c}80.54 \pm 10.65 \text { (pie) } \\
112.16 \pm 4.79 \text { (chip) }\end{array}$ \\
\hline & $\begin{array}{l}\text { Cookies } \\
\text { (butter) }\end{array}$ & ND-2.07 & ND-65.4 & $36-432$ & $1.17 \pm 0.06$ & $7.97 \pm 1.51$ & $102.02 \pm 8.87$ \\
\hline & Potato Chip & - & - & $117-2,762$ & ND & ND & $369.40 \pm 30.13$ \\
\hline
\end{tabular}

times of the standard deviation and 10 times of standard deviation for LOQ. LOD and LOQ values are shown in Table 3. LOD of HCAs was in the range $0.02 \sim 1.55 \mathrm{ng} / \mathrm{mL}$, $0.15 \sim 2.32 \mathrm{ng} / \mathrm{g}$ and $0.23 \sim 2.59 \mathrm{ng} / \mathrm{g}$ for non-fat liquid, nonfat solid and fat solid, respectively. Even though these matrices are different with those of the literature, LODs are similar level with previous LODs ranged in $0.05 \sim 4 \mathrm{ng} / \mathrm{g}$ (25), which are appropriate for the HCAs analysis in the total diet study. For acrylamide, LOD was $2.69 \mathrm{ng} / \mathrm{mL}, 3.07$ $\mathrm{ng} / \mathrm{g}$ and $3.00 \mathrm{ng} / \mathrm{g}$ for non-fat liquid, non-fat solid and fat solid, respectively, which are also adequate level compared with the literature data, $0.1 \sim 10 \mathrm{ng} / \mathrm{g}(26,27)$.

Considering all these validation results, these methods for three kinds of matrices are reliable and accurate at a low concentration level $(\mu \mathrm{g} / \mathrm{kg})$ for the quantitation of HCAs and acrylamide in agricultural products.

Application to real samples. To evaluate the applicability of the proposed method, eight types of agricultural products (apple juice, vinegar, flour, cereal, jam, chocolates, cookie and potato chip) purchased from 18 retail markets from nine cities (South Korea) were analysed by the optimized analytical procedures.

In the previous study, HCAs in different foodstuffs after heating or cooking were as follows: in egg, MeIQx, Trp-P-1 and $\mathrm{PhIP}$ in the ranges of $0.32 \sim 4.08,0.14 \sim 3.24$ and $0.33 \sim$ $5.42 \mathrm{ng} / \mathrm{g}$, respectively (19); in soybean product, IQ, MeIQx, $\mathrm{PhIP}$, and $\mathrm{A} \alpha \mathrm{C}$ in the ranges of 0.13 1.96, 0.52 6.74, 0.03 6.45 and $0.23 \sim 1.85 \mathrm{ng} / \mathrm{g}$, respectively (19); in wine, IQ, Glu-P-2, PhIP and MeA $\alpha \mathrm{C}$ in the ranges of 10, 8, 12.3 83 and $15 \sim 107 \mathrm{ng} / \mathrm{L}$ (18); in beer, PhIP in the range of 8.0
$25.1 \mathrm{ng} / \mathrm{L}$ (28); and in the processed spices, IQ and MeIQx in the ranges of 2.1 9.6 and 8.9 12.3, respectively (23). Acrylamide was $11 \sim 1,057 \mathrm{ng} / \mathrm{g}$ in cereals, not detected (ND)-909 ng/g in chocolates, 36 432 ng/g in cookies, 117 $2,762 \mathrm{ng} / \mathrm{g}$ in potato chips (26), and ND-889 $\mathrm{ng} / \mathrm{g}$ in tea products (27).

In this study, among the 12 HCAs and acrylamide, only harman, norharman and acrylamide were detected from eight samples. Harman and norharman were detected in the range of ND-8.50 ng/g, and concentrations of acrylamide were in the range of ND-369.4 ng/g. These results are similar to or below the reported data (Harman: ND-91.7, norharman: ND-187.4, acrylamide: ND-2,762 ng/g) as shown in Table 4.

In conclusion, analytical methods using the LC-MS/MS MRM mode to detect 12 species of HCAs (IQ, MeIQ, GluP-1, Glu-P-2, MeIQx, Trp-P-1, Trp-P-2, PhIP, AaC, MeAaC, Harman, and Norharman) and acrylamide formed mainly by the Maillard reaction were established using six isotope labelled internal standards (IQ- $\mathrm{d}_{3}$, MeIQx- $\mathrm{d}_{3}$, PhIP-d $\mathrm{d}_{3}$, Trp$\mathrm{P}-2-{ }^{13} \mathrm{C}_{2^{-}}{ }^{15} \mathrm{~N}$, MeAaC- $\mathrm{d}_{3}$, and $\mathrm{AA}-{ }^{13} \mathrm{C}_{3}$ ) in agricultural foods. The established method was successfully evaluated using the parameters according to the CODEX guideline CAC/GL 71-2009 and showed good precision, accuracy and recovery. Detection limits were in the adequate range for all analytes and this method was successfully applied to real samples. It could be used as a promising analytical method to monitor HCAs and acrylamide for the risk assessment in the total diet study and the results of real sample analysis may be used as a preliminary data for the strategy on the reduction of hazardous compounds in the food. 


\section{ACKNOWLEDGEMENTS}

This study was supported by a grant (13162MFDS049) from Ministry of Food and Drug Safety in 2013-2014.

\section{REFERENCES}

1. Felton, J.S., Malfatti, M.A., Knize, M.G., Salmon, C.P., Hopmans, E.C. and Wu, R.W. (1997) Health risks of heterocyclic amines. Mutat. Res., 376, 37-41.

2. Skog, K.I., Johansson, M.A. and Jagerstad, M.I. (1998) Carcinogenic heterocyclic amines in model systems and cooked foods: a review on formation, occurrence and intake. Food Chem. Toxicol., 36, 879-896.

3. Tekkeli, S.E.K., Önal, C. and Önal, A. (2012) A review of current methods for the determination of acrylamide in food product. Food Anal. Methods, 5, 29-39.

4. Lee, M.R., Chang, L.Y. and Dou, J. (2007) Determination of acrylamide in food by solid-phase microextraction coupled to gas chromatography-positive chemical ionization tandem mass spectrometry. Anal. Chim. Acta, 582, 19-23.

5. Hoenicke, K., Gatermann, R., Harder, W. and Hartig, L. (2004) Analysis of acrylamide in different foodstuffs using liquid chromatography-tandem mass spectrometry and gas chromatography-tandem mass spectrometry. Anal. Chim. Acta, 520, 207-215.

6. Şenyuva, H.Z. and Gökmen, V. (2006) Interference-free determination of acrylamide in potato and cereal-based foods by a laboratory validated liquid chromatography-mass spectrometry method. Food Chem., 97, 539-545.

7. Ohgaki, H., Takayama, S. and Sugimura, T. (1991) Carcinogenicities of heterocyclic amines in cooked food. Mutat. Res., 259, 399-410.

8. International Agency for Research on Cancer (IARC). (1993) IARC Monographs on the evaluation of carcinogenic risk to humans (volume 56). Lyon, France, pp. 165-229.

9. Rosén, J. and Hellenäs, K.E. (2002) Analysis of acrylamide in cooked foods by liquid chromatography tandem mass spectrometry. Analyst, 127, 880-882.

10. Chen, Y.H., Xia, E.Q., Xu, X.R., Ling, W.H., Li, S., Wu, S., Deng, G.F., Zou, Z.F., Zhou, J. and Li, H.B. (2012) Evaluation of acrylamide in food from China by a LC/MS/MS method. Int. J. Environ. Res. Public Health, 9, 4150-4158.

11. LoPachin, R.M. (2004) The changing view of acrylamide neurotoxicity. Neurotoxicology, 25, 617-630.

12. Gross, G.A. (1990) Simple method for quantifying mutagenic heterocyclic aromatic amines in food products. Carcinogenesis, 11, 1597-1603.

13. Gross, G.A. and Gruter, A. (1992) Quantitation of mutagenic/ carcinogenic heterocyclic aromatic amines in food products. $J$. Chromatogr. A, 592, 271-278.

14. Polak, T., Andrenšek, S., Žlender, B. and Gašperlin, L. (2009) Effects of ageing and low internal temperature of grilling on the formation of heterocyclic amines in beef Longissimusdorsi muscle. Food Sci. Technol., 42, 256-264.

15. Zhang, Y., Lin, C., Fang, G., Mei, J., Wang, X. and Wang, S. (2012) Tandem solid phase extraction coupled to LC-ESI-MS/ MS for the accurate simultaneous determination of five het- erocyclic aromatic amines in processed meat products. Eur. Food Res. Technol., 234, 197-205.

16. Sun, L., Zhang, F., Yong, W., Chen, S., Yang, M.L., Ling, Y., Chu, X. and Lin, J.M. (2010) Potential sources of carcinogenic heterocyclic amines in Chinese mutton shashlik. Food Chem., 123, 647-652.

17. Stavric, B., Lau, B.P., Matula, T.I., Klassen, R., Lewis, D. and Downie, R.H. (1997) Mutagenic heterocyclic aromatic amines (HAAs) in 'processed food flavour' samples. Food Chem. Toxicol., 35, 185-197.

18. Richling, E., Decker, C., Haring, D., Herderich, M. and Schreier, P. (1997) Analysis of heterocyclic aromatic amines in wine by high-performance liquid chromatography-electrospray tandem mass spectrometry. J. Chromatogr. A, 791, 7177.

19. Lan, C.M. and Chen, B.H. (2002) Effects of soy sauce and sugar on the formation of heterocyclic amines in marinated foods. Food Chem. Toxicol., 40, 989-1000.

20. Janoszka, B., Blaszczyk, U., Damasiewicz-Bodzek, A. and Sajewicz, M. (2009) Analysis of heterocyclic amines (HAs) in pan-fried pork meat and its gravy by liquid chromatography with diode array detection. Food Chem., 113, 1188-1196.

21. Alves, R.C., Soares, C., Casal, S., Fernandes, J.O. and Oliveira, M.B.P.P. (2010) Acrylamide in espresso coffee: influence of species, roast degree and brew length. Food Chem., 119, 929934.

22. Andrzejewski, D., Roach, J.A., Gay, M.L. and Musser, S.M. (2004) Analysis of coffee for the presence of acrylamide by LC-MS/MS. J. Agric. Food Chem., 52, 1996-2002.

23. Richling, E., Kleinschnitz, M. and Schreier, P. (1999) Analysis of heterocyclic aromatic amines by high resolution gas chromatography-mass spectrometry: a suitable technique for the routine control of food and process flavours. Eur. Food Res. Technol., 210, 68-72.

24. US Food and Drug Administration (FDA). (2003) Draft: Detection and quantitation of acrylamide in foods. Available from: http://www.fda.gov/Food/FoodborneIllnessContaminants/ Chemical Contaminants.

25. Pais, P., Moyano, E., Puignou, L. and Galceran, M.T. (1997) Liquid chromatography-electrospray mass spectrometry with in-source fragmentation for the identification and quantification of fourteen mutagenic amines in beef extracts. J. Chromatogr. A, 775, 125-136.

26. Roach, J.A., Andrzejewski, D., Gay, M.L., Nortrup, D. and Musser, S.M. (2003) Rugged LC-MS/MS survey analysis for acrylamide in foods. J. Agric. Food Chem., 51, 7547-7554.

27. Lee, S., Yoo, M., Koo, M., Kim, H.J., Kim, M., Park, S.K. and Shin, D. (2013) In-house-validated liquid chromatographytandem mass spectrometry (LC-MS/MS) method for survey of acrylamide in various processed foods from Korean market. Food Sci. Nutr., 1, 402-407.

28. Manabe, S., Suzuki, H., Wada, O. and Ueki, A. (1993) Detection of the carcinogen 2-amino-1-methyl-6-phenyl-imidazo[4,5-b]pyridine (PhIP) in beer and wine. Carcinogenesis, 14, 899-901.

29. Herraiz, T. (2004) Relative exposure to $\beta$-carbolinesnorharman and harman from foods and tobacco smoke. Food Addit. Contam., 21, 1041-1050. 